\title{
Is there a bright side? The positive emotional responses of mothers of children with learning difficulties
}

\section{Cheryl Williams}

\author{
Educational Psychology, Faculty of Education, University of Pretoria
}

A registered educational psychologist who runs a private practice on a part-time basis, Cheryl Williams currently holds the part-time position of tutor in the Department of Educational Psychology at the University of Pretoria, which involves learning support to students from first year level up to Master's level. She is a part-time lecturer within the Department for one of the first year education modules, as well as a lecturer involved in the Department's ACE (Special Needs) Distance Education Programme. She is involved with voluntary counseling in her community church.

\section{Irma Eloff}

\section{Educational Psychology, Faculty of Education, University of Pretoria}

The acting dean of the Faculty of Education at the University of Pretoria, Irma Eloff is a registered educational psychologist. Her research focuses on Positive Psychology and the use of asset-based approaches in the contexts of HIV \& AIDS, inclusive education and early intervention. Her teaching involves the field of learning support for master's degree students in Educational Psychology. In 2001-2002 she was a visiting professor in the Department of Psychology at Yale University. She is the author and editor of numerous book publications in Educational Psychology.

\begin{abstract}
The focus of this article is on the positive emotional responses of mothers to children with learning difficulties. Initially, a narrative research design, within a constructivist and interpretivist paradigm, was used to capture a chapter in the life stories of eleven mothers whose children were attending a school specialising in 'remedial' education, relating their experiences and emotional responses regarding their child's learning difficulties. A subsequent theme analysis focused on the positive emotional responses of these mothers to their children. The study found substantial evidence of positive emotional responses towards the children as well as the school where support was provided. Results indicate strong responses of love, happiness, understanding, relief, acceptance and hopefulness in the majority of the participants.
\end{abstract}

Key words: Positive psychology; learning difficulties; mothers' emotional responses.

\section{Introduction: Mothers sidelined and misrepresented}

There is a vast amount of literature focusing on the difficulties that children with learning difficulties and their parents may experience. Most of the references to parents of children with learning difficulties in the literature are, however, on an informative and supportive level, i.e. for parents to understand what their child is coping with and how they will be able to support him/her in the various skills that need to be developed. What literature that does exist shows that often only 
nominal attention is given to parents' experiences and emotional responses and makes little distinction between those of mothers and of fathers. Parents are referred to as one group, where it is assumed that mothers' and fathers' responses to their child with learning difficulties are the same. Fairly little information exists about the emotions that mothers go through when their child is experiencing learning difficulties. These emotions can have an impact on how mothers are able to cope, and on how they view themselves as mothers, and in this way are able to understand and support their child. Where parents are referred to as an homogeneous category, the assumption is that both mothers and fathers experience the same emotions. This assumption may be as correct as it may be incorrect.

This research study, therefore, specifically examines the emotional responses of mothers to their child with learning difficulties, thereby contributing towards the minimal amount of existing literature that does reflect a gender differentiation. It focuses on a particular section of the data that emerged from a broader study (Williams, 2004) on the emotional responses of mothers, in which it became evident that a substantial amount of the data was pointing towards positive emotional responses. In turn, this led to an additional research question:

What are the positive emotional responses of mothers to children with learning difficulties?

This refined focus within the broader study aligns with recent trends in the field of psychology that have seen a movement away from a problem-focused stance to a more positive, solutionfocused emphasis. Individuals are increasingly seen as existing within unique contexts, consisting of strengths and resources that are assets to the individual. Each individual also has inner strengths and resources. These assets, both internal and external, are progressively viewed as crucial to the effectiveness of support and the planning of intervention. In line with this trend in psychology, this article therefore focuses on the positive emotional responses that were reported by the mothers in this study.

\section{Rationale, place and participants}

The rationale for the focus of this article is seated on the assumption that positive emotional responses of mothers to children with learning difficulties are equally important as negative emotional responses. Yet, as psychologists, we have a tendency to lean towards negative emotional responses, since this has been the origin of our science, e.g. providing support for dealing with 'negative' emotions. We believe that this exploration of positive emotional responses can contribute constructively to our theoretical understanding of the complexities of the dynamics between mothers and their children with learning difficulties. Regarding the inclusion of cross-cultural issues within this field, we considered that they are a vast and complex field that whilst impacting on the results of the study might detract from its immediate focus. Fully acknowledging their importance, we nevertheless found it more practical at this stage to focus on the commonalities of the experiences of mothers with children with learning difficulties.

The participants for this research study were selected from a school specialising in 'remedial' education in the Gauteng province of South Africa. Each participant was a mother of a child who at the time was attending this school. The school provides learning opportunities from grade 0 up to grade 7, with approximately 160 learners in total. Each grade consists of two classes with 
eleven learners in each, except for grade 0 , which has one class of approximately five to nine learners. The school staff consists of fifteen educators, who have training in special educational needs ('remedial' teaching), three occupational therapists, three speech therapists, two part-time psychologists and a resource teacher (specialist in learning support).

The majority of learners in the school have experienced a degree of learning challenges within mainstream schooling. Before a learner is accepted at the school, various comprehensive assessments are made, e.g. occupational, speech, psychological and generic educational/scholastic. These assessments inform the kind of support the learner will need in the school. The full remedial programme for the learner takes place during the school day, with the children receiving substantial individual attention. The staff-learner ratio is about one staff member for every five children.

The staff at the school are dedicated, highly qualified and experienced in working with learners with learning difficulties. The aim is to provide support for learning and if possible to facilitate placement back into mainstream schools. The therapists and teachers work closely together as a multidisciplinary team holding bi-weekly case conferences. The class teacher, occupational therapist, speech therapist, psychologist and school principal are present at these conferences. The team meets to decide the most appropriate intervention strategy for the child and the parents receive a verbal and a written evaluation report the following week.

Participants for this study were selected through purposive sampling, with the following criteria in mind: Each was a mother of a child experiencing learning difficulties and enrolled at the school specialising in 'remedial' education. In total, twelve interviews took place, of which eleven were used for the purpose of data analysis. One interview was excluded as the participants included both a mother and father, and the information provided was therefore unsuitable for the focus of this study (i.e. on the mothers).

The eleven mothers included in this study were aged from 36 to 53 years, with the average being 43. Out of the 11 participants selected, seven had a son and four a daughter attending the school. The children of the mothers were between the ages of six and 12 and ranged from grade 0 to grade 6 learners. Four of the children were the youngest in their family, four the oldest and two had both older and younger siblings. One child was an only child. There were nine mothers who were married, one divorced, one in the process of possibly divorcing and one who had never been married. Two mothers reported having another child with learning difficulties, seven as having a relative with learning difficulties, and four with no known relative with learning difficulties. Four mothers mentioned that they themselves and/or their husband experienced learning difficulties. Seven reported coping adequately at school, themselves. Table 1 gives a brief description of each participant. 
Table 1: Descriptions of the participants in this study

\begin{tabular}{|c|c|}
\hline Participant & Description \\
\hline 1 & $\begin{array}{l}43 \text { years old, divorced and working as a housewife. She has a seven-year-old } \\
\text { boy in grade } 1 \text { at the 'remedial' school, who has ADD, as well as four other } \\
\text { children, two boys, aged three and } 12 \text { years and a daughter, aged } 14 \text { years, } \\
\text { none of whom have learning difficulties. Her ex-husband's brother was } \\
\text { diagnosed with ADD. }\end{array}$ \\
\hline 2 & $\begin{array}{l}41 \text { years old, married for } 19 \text { years and running own business as a development } \\
\text { consultant in the socio-economic field. She has a 10-year-old boy in grade } 4 \\
\text { at the 'remedial' school, as well as another son, aged nine, who experiences } \\
\text { no learning difficulties. Her husband's two brothers each have a son with } \\
\text { learning difficulties and her sister a son with learning difficulties. }\end{array}$ \\
\hline 3 & $\begin{array}{l}47 \text { years old, married for } 22 \text { years and working as a housewife. She has an 11- } \\
\text { year-old boy in grade } 5 \text { at the 'remedial' school, as well as two other children, } \\
\text { a daughter, aged } 17 \text { and a son, aged 19, neither of whom has learning difficulties. } \\
\text { There is no known relative with learning difficulties. }\end{array}$ \\
\hline 4 & $\begin{array}{l}45 \text { years old, married for } 11 \text { years and working in public relations. She has } \\
\text { a six-year-old girl in grade } 0 \text { at the 'remedial' school, as well as two other } \\
\text { daughters, aged five and eight, neither of whom have learning difficulties. } \\
\text { According to the participant there is a possibility that her husband's sister } \\
\text { may have had learning difficulties. }\end{array}$ \\
\hline 5 & $\begin{array}{l}43 \text { years old, married for } 16 \text { years and, although she currently does not work, } \\
\text { has a teaching qualification. She has a seven-year-old boy in grade } 1 \text { at the } \\
\text { 'remedial' school but no other children. There is no known relative with } \\
\text { learning difficulties. }\end{array}$ \\
\hline 6 & $\begin{array}{l}41 \text { years old, married for } 15 \text { years and working as a hairdresser. She has a } 10 \text { - } \\
\text { year-old girl in grade } 4 \text { at the 'remedial' school, as well as a son, aged } 14 \text {, who } \\
\text { does not experience any learning difficulties. The mother, herself, has learning } \\
\text { difficulties. }\end{array}$ \\
\hline 7 & $\begin{array}{l}39 \text { years old, married for } 14 \text { years and working as a housewife. She has an 11- } \\
\text { year-old girl in grade } 4 \text { at the 'remedial' school, as well as twin girls, aged 13, } \\
\text { one of whom experienced learning difficulties. There is no known relative } \\
\text { with learning difficulties. }\end{array}$ \\
\hline 8 & $\begin{array}{l}53 \text { years old, never married and working as a baker. She has a } 12 \text {-year-old girl } \\
\text { in grade } 6 \text { at the 'remedial' school, as well as another daughter, aged } 21 \text {, who } \\
\text { experiences learning difficulties. Her child's paternal aunt had learning } \\
\text { difficulties. }\end{array}$ \\
\hline
\end{tabular}




\begin{tabular}{|l|l|}
\hline Participant & Description \\
\hline 9 & $\begin{array}{l}36 \text { years old, married for } 13 \text { years and working as an estate agent. She has a } \\
12 \text {-year-old boy in grade } 6 \text { at the 'remedial' school, as well as another son, } \\
\text { aged 10, who does not experience learning difficulties. Both she and her } \\
\text { husband experience learning difficulties. }\end{array}$ \\
\hline 10 & $\begin{array}{l}37 \text { years old, married for } 12 \text { years and working in her husband's business. } \\
\text { She has an 11-year-old boy in grade } 5 \text { at the 'remedial' school, as well as a } \\
\text { daughter, aged six, who does not experience learning difficulties. There is no } \\
\text { known relative with learning difficulties. }\end{array}$ \\
\hline 11 & $\begin{array}{l}39 \text { years old, in the process of divorcing and working as a business manager. } \\
\text { She has a nine-year-old boy in grade } 3 \text { at the 'remedial' school, as well as } \\
\text { another son, aged five, who does not experience learning difficulties. Her } \\
\text { husband has learning difficulties. }\end{array}$ \\
\hline
\end{tabular}

\section{Data collection}

\section{Interviews}

Semi-structured interviews were conducted with all 11 participants, with permission requested to audiotape the interview for the purpose of transcribing. The researcher had an interview schedule prepared, with questions being asked in a relatively set order. At the outset of the interview, participants were encouraged to tell their story and to elaborate on any aspects they wished to. The questions guided the interview towards the focus of this study and in addition encouraged participants to speak freely. Unplanned probes and additional questions were used during the interviews where deemed necessary. Most of the mothers spoke with ease about their experience of the child's difficulties, with little need for too many unplanned questions.

Interview questions in this study were related to aspects of Creswell's (2002) three-dimensional space narrative structure, which involves looking inward at the participant's feelings, hopes, reactions and dispositions, and outward at social interaction to include other people and their intentions, purposes, assumptions and points of view. There is a consideration of the past that is remembered, the present relating to experiences of an event, and the future, looking forward to possible experiences.

Interviews were transcribed by presenting the interview format in terms of speaker turn units. In other words, the conversation was broken up into consecutively numbered units for each turn taken by the researcher and the participant.

\section{Field notes}

The transcribed interviews, as well as the letters written by the participants (see below), were the central field notes used for data-analysis in this study. The personal experience of the researcher 
is an integral part of the research process (Ezzy, 2002) and therefore cannot be ignored. This was particularly important in this study as the interaction between the researcher and participants involved empathic listening and therefore a degree of subjectivity. Field notes were included in the form of journal entries consisting of reflections written by the researcher throughout the research process. These field notes were written after contact with participants, especially after each interview session.

Field notes in the form of journal entries written by the researcher provided a reflective balance (Clandinin \& Connelly, 2000). The research journal in this study was used to reflect on the practicalities of conducting the research and emergent interpretations of the significance of data collected (Ezzy, 2002). The research journal facilitated the interpretative process that was at the heart of this qualitative study. It encouraged the researcher to reflect routinely on her emerging understanding of the data.

\section{Letters from participants}

Participants were asked to write a letter reflecting on their experiences regarding their child's learning difficulties, with specific emphasis on the emotions they had experienced, as well as their view of themselves as parents. In addition to this, part of the letter concerned a reflection on the experience of telling their story by means of the interview. The participants were provided with self-addressed, stamped envelopes at the end of the interview and given a choice of either posting their letters or leaving them at the school, where the researcher would collect them. They were permitted to keep their letters anonymous if they wished. The response rate for returning the letters was average, with five of the eleven doing so. Follow-up telephone calls were made three times and then discontinued.

\section{Feedback and collaboration session with participants}

The broader study followed a narrative research design that aimed at collaborating with the participants when writing the research study (Creswell, 2002), so that evolving interpretations of the data could be checked with participants (Ezzy, 2002). A feedback session with each participant was held after completion of the initial levels of data analysis. The purpose of this session was to inform participants of and discuss with them the initial findings of the study and to receive their input regarding these findings. Further data was collected through note-taking during this session regarding the input from participants. Aguinis and Henle (2002) regard this debriefing as the primary method used to ensure that participants receive the information on the findings that is often promised as a benefit of participating in research. This they argue leaves participants with a sense of dignity and a perception that their time was not wasted.

\section{Data analysis}

During the data analysis stage, open coding was first applied. All eleven transcribed interviews were read, after which emotional responses were listed, based on the main emotional responses that seemed to be prominent in all the stories. Axial coding (Ezzy, 2002) was applied as a second step, with specific responses highlighted in the transcribed interviews, specifically distinguishing between experiences, behaviour, thoughts, opinions and emotions. Specific attention was paid to 
the emotional responses reported by the participants. In this regard Egan (2002) states that one should pay careful attention to three aspects when listening to stories, namely the person's experiences (what happens to them), their behaviour (what they do and do not do) and their affect (feelings, emotions and moods). Each of these aspects was highlighted in a different colour and notes made in the margins. The letters from the participants were also highlighted in the same manner. Thereafter these emotional responses were tabulated, according to themes, vertically down the left-hand side, and the participants numbered from 1 to 11 horizontally across the top of the page. A marker was put under each participant who mentioned a particular theme, along with the speaker turn unit number evidencing that response. Important opinions and thoughts were included in this step, so as not to lose any important data. It resulted in 129 'themes'.

Finally, the concept of selective coding, as described by Ezzy (2002) was used. This involved the identification of the core category or story around which the analysis focused, namely emotional responses, with 23 themes identified. These themes were integrated from the 129 full 'themes', with the focus now specifically on emotional responses reported. Each of the 23 emotional response themes included sub-themes, which refer to specific aspects of contexts of these emotional responses. The layout in tabular format was the same for the 23 emotional response themes as for the 129 'themes', where it was possible to see the total number of participants who mentioned the emotional response, as well as more specifically how many participants mentioned the sub-themes relating to specific contexts. Again speaker turn unit numbers were included for easy reference to the supporting data.

Through further examination and organisation of the results there was a reduction from 23 emotional response themes to 18 . Some emotional response themes were merged together as the meaning or understanding thereof was closely related. For instance, pride was included under feelings of love. Three emotional responses were removed from the primary results and included under exceptions, as a minority of mothers (two) reported experiencing them. Any emotional responses, where at least six mothers (more than half) reported experiencing them, were included under primary responses, as this was regarded as indicative of a 'strong' theme.

To organise the data analysis results more efficiently and present them in a coherent manner, the 18 emotional response themes were then categorised under the four basic emotion categories, namely, fearful responses, sad responses, angry responses and joyful responses. During this level of analysis a theme map was used in order to create a visual representation of the emerging interpretation and to draw together the initial narrative. The intention of this strategy was to capture the qualitative richness of the phenomenon (Boyatzis, 1998).

At this point it became apparent that the joyful emotional responses represented a substantial segment of the overall emotional responses of the mothers to their children with learning difficulties. The joyful emotional responses were clustered around love, happiness, understanding, relief, acceptance and hopefulness.

\section{Results: Thematic presentation of positive responses}

The results below indicate the joyful emotional responses that were reported by mothers of children with learning difficulties during this study. 


\section{Love}

...he's always been my sort of "hartskind" [heart-child]...I've always had a soft spot for him... I just love him so much...'(Participant 11, unit 66).

Table 2: Emotional response theme: Love

\begin{tabular}{|l|l|}
\hline \multicolumn{2}{|c|}{ LOVE } \\
\hline Definition & An intense affectionate concern for another person (Morris, 1973:772). \\
\hline Indicators & $\begin{array}{l}\text { All the instances from the raw data where participants used phrases such as } \\
\text { 'adore', 'proud of', 'admire', 'nice to be with', 'easy child', 'love' or 'being there' } \\
\text { were considered to be illustrative of this theme. }\end{array}$ \\
\hline Exclusions & $\begin{array}{l}\text { Instances from the raw data where participants referred to 'happiness', 'relief', } \\
\text { 'understanding' or 'acceptance' were not considered to be related to this theme. } \\
\text { Although there are similarities between these, they are separated for the } \\
\text { purposes of this study. }\end{array}$ \\
\hline Exceptions & $\begin{array}{l}\text { This refers to responses where one or more participants indicated opposite } \\
\text { responses to those of the majority of the participants. It may also indicate that } \\
\text { they did not express this particular emotional response at all. }\end{array}$ \\
\hline
\end{tabular}

In total, all eleven mothers reported experiencing feelings of love and caring for their child and saw this as a way of supporting their child, which they expressed a desire to do, in whatever manner they could. This theme is supported by the following quotations:

- 'I've supported him just by being there for him... lots of love, which he gets... the love is there unconditionally' (Participant 5, unit 44).

- '...we got her through the thing and not by buying her with things... by love and care' (Participant 7, unit 70).

- 'I adore him and I think he's got a very beautiful nature...I look at that face and there's goodness radiating out of it...I admire him...I'm very proud of him' (Participant 1, unit 104).

- 'He's a very caring child... a very loving child... he's a happy kid...he's nice to be with...' (Participant 2, unit 112).

- '... and she really is a pleasure, she's an absolute pleasure...she's lovely' (Participant 4, unit 56).

- '...she's really such a sweet little kid...she's a very lovable child...'(Participant 6, unit 108).

- 'Ill support her in whatever way there is...' (Participant 7, unit 96).

- 'I've supported her by...I'm just understanding and loving and caring... helping her where I can... and encouraging her...' (Participant 8, unit 62).

- 'I support him by being his shoulder to cry on when he comes home and he's had a hard day... and to encourage him just to keep going' (Participant 9, unit 80).

- 'I've supported him by just being there all the time' (Participant 10, unit 96). 


\section{Happiness}

'It made me very happy that he could cope better at school...' (Participant 5, unit 14).

Table 3: Emotional response theme: Happiness

\begin{tabular}{|l|l|}
\hline \multicolumn{2}{|c|}{ HAPPINESS } \\
\hline Definition & $\begin{array}{l}\text { Feeling or showing pleasure or contentment; fortunate; apt; pleasing (Allen, } \\
1984: 335) \text {. Having or demonstrating pleasure or satisfaction (Morris, 1973:599). }\end{array}$ \\
\hline Indicators & $\begin{array}{l}\text { All the instances from the raw data where participants used phrases such as } \\
\text { 'feel happy', 'felt blessed', 'felt good', 'feel comfortable', 'the right decision', } \\
\text { 'feel positive', 'felt excited', 'felt delighted', 'it's fantastic', 'feel pleased', 'feel } \\
\text { glad',feel good' or 'feel confident' were considered to be illustrative of this } \\
\text { theme. }\end{array}$ \\
\hline Exclusions & $\begin{array}{l}\text { Instances from the raw data where participants referred to 'relief', } \\
\text { 'understanding', 'love' or 'hopefulness' were not considered to be related to } \\
\text { this theme. Although there are similarities between these, they are separated } \\
\text { for the purposes of this study. }\end{array}$ \\
\hline Exceptions & $\begin{array}{l}\text { This refers to responses where one or more participants indicated opposite } \\
\text { responses to that of the majority. It may also indicate that they did not express } \\
\text { this particular emotional response at all. There were no exclusions for the } \\
\text { emotional response of happiness. }\end{array}$ \\
\hline
\end{tabular}

In total, all eleven mothers expressed experiencing feelings of happiness, for instance at their child being accepted at the 'remedial' school and receiving education there. They expressed the view that it was an 'exceptional', 'fantastic' school with full, specialised 'remedial' support. Mothers felt that their child had improved scholastically as a result of being at the school, that it had given him or her a chance and that s/he would not be coping as well in a mainstream school. Mothers also felt happy at seeing the emotional improvement in their child being at the 'remedial' school, for example, with increased self-confidence in the child. This sub-theme is supported by the following quotations:

- '...I feel good...I think without this school... he wouldn't have a chance' (Participant 1, unit 122).

- '...we feel very comfortable with the school he's at now... the confidence that he lost last year has been restored. He's done well, so he doesn't have like any issues or problems with himself as a result of his learning difficulty...so we feel very happy...' (Participant 2, units 40 \& 42).

- '... II feel] very, very positive... having put him into a remedial school, where he can cope and he can deal and he can feel confident and things like that...very positive' (Participant 3, unit 32). 
- 'I think it's a fantastic school...it's one of the biggest things I was happy about...' (Participant 4, unit 68).

- '...we were just so happy to go to this school...it's the best chance your child has got...' (Participant 4, unit 94).

- '...it makes us happier to know that he was happy...our main thing in life is as long as he's happy, he's comfortable and there's no emotional trauma in his life, that makes us happy... (Participant 5, unit 24).

- '... at the moment I'm sort of happier that she's doing alright...I'm sort of happy that she feels alright' (Participant 6, unit 196).

- 'I'd be happy to keep her there [at the remedial school]...' (Participant 6, unit 240).

- 'When I see the change in my child, I was happy... she's reading fluently, she can spell, she can do her maths, everything...' (Participant 7, units $16 \& 20)$.

- 'I feel very positive...one wants to do the best for your child...it's a great school... they've been very good to her...she's doing okay...' (Participant 8, unit 24).

- 'I'm very positive because she's coping very well...I'm so happy'(Participant 8, unit 32).

- '...I had a meeting with [his teacher] and all the therapists to see how he's going... and everything was positive... so I feel very happy...everything's just good' (Participant 9, units 22 $\& 24)$.

- 'Since he's been at the school there's been a positive shift towards something better... some days it's almost as if there aren't any learning difficulties' (Participant 9, units $28 \& 30$ ).

- 'I felt happiness seeing my child change over the last year and a half at [the remedial school], which has been wonderful. He has come out of himself. He is just blossoming... he is always eager to go to school... he has come through yet another milestone and is just joyful' (Participant 9 , letter).

- 'I was happy about it...I was fine because it is a good school, especially for that kind of problem...'(Participant 10, units $8 \& 12$ ).

\section{Understanding}

'I've learnt how to... understand the situation and what she's going through...that helped me to get to where I am now...' (Participant 8, unit 104).

Table 4: Emotional response theme: Understanding

\begin{tabular}{|l|l|}
\hline \multicolumn{2}{|c|}{ UNDERSTANDING } \\
\hline Definition & $\begin{array}{l}\text { To grasp or comprehend meaning; to have understanding, knowledge or } \\
\text { comprehension; having or characterised by comprehension, good sense or } \\
\text { discernment (Morris, 1973:1397). }\end{array}$ \\
\hline Indicators & $\begin{array}{l}\text { All the instances from the raw data where participants used phrases such as } \\
\text { 'understand', 'gained knowledge', 'know better', 'find out more' or 'realised' were } \\
\text { considered to be illustrative of this theme. }\end{array}$ \\
\hline
\end{tabular}




\begin{tabular}{|l|l|}
\hline Exclusions & $\begin{array}{l}\text { Instances from the raw data where participants referred to 'relief' or 'acceptance' } \\
\text { were not considered to be related to this theme. Although there are similarities } \\
\text { between these, they are separated for the purposes of this study. }\end{array}$ \\
\hline $\begin{array}{l}\text { Exceptions } \\
\text { responses }\end{array}$ & $\begin{array}{l}\text { This refers to responses where one or more participants indicated opposite } \\
\text { to those of the majority of the participants. It may also indicate that they did not } \\
\text { express this particular emotional response at all. }\end{array}$ \\
\hline
\end{tabular}

In total, six mothers reported experiencing feelings of understanding, five mentioning reading up on their child's difficulties and speaking to people as factors that led to feelings of understanding. They reported that they now had a better understanding of their child and how things work. Mothers reported that they understood that it was not their child's fault that he or she struggled academically or had difficulty in concentrating in class. Mothers felt they were better able to support their child because of their increased understanding. This sub-theme is supported by the following quotations:

- 'I was reading about it... whatever I could read about it...you understand it's not his fault' (Participant 1, unit 32).

- 'I understand him... how he reacts and why he reacts like that... it just makes it easier' (Participant 1, unit 92).

- 'I've sort of gone out of my way to find out a little bit more about what happened and what goes on...so it has been an incredibly positive experience' (Participant 3, unit 48).

- '...I would definitely recommend that people in a similar position to myself, when first I found out about the problem, having understanding regarding the problem...' (Participant 8, letter).

- 'I've done a lot of reading... which has helped me to understand better...because when you start reading books... you start to realise that you're not sort of the only parent going through this...you also find positive things that help you carry on...I like to learn things that are going to help me...' (Participant 9, units 56, $58 \& 60$ ).

- '...I also read up a lot about it... and you realise, but there's nothing really that much wrong with him. He's got a few problems, but he's not that bad...I've made an effort to find out what's going on out there' (Participant 11, units $52 \& 54$ ).

Two mothers, who themselves had learning difficulties, reported that they felt they could better understand their child and what he or she was going through, and mentioned that they could identify with their child. This sub-theme is supported by the following quotations:

- '...I've also had the same problems, so I understand what she's going through...' (Participant 6, unit 64).

- 'I also struggled at school...I still struggle with some things some days...when [he] started with this problem it was like...I identified with a lot of what he was going through, because I was also in the same boat...I could understand what he was going through...it helped me to understand his situation' (Participant 9, units 38, $40 \& 42$ ). 
Five mothers did not report experiencing feelings of understanding during the course of this study, although they did not necessarily all report feelings of not understanding.

\section{Relief}

'...when he was accepted at the school I was relieved...' (Participant 9, unit 18).

Table 5: Emotional response theme: Relief

\begin{tabular}{|c|c|}
\hline \multicolumn{2}{|r|}{ RELIEF } \\
\hline Definition & $\begin{array}{l}\text { Anything that lessens pain, discomfort, fear, anxiety or the like (Morris, } \\
\text { 1973:1098). }\end{array}$ \\
\hline Indicators & $\begin{array}{l}\text { All the instances from the raw data where participants used phrases such as "is } \\
\text { a relief", "feel relaxed", "don't worry", "done the right thing", "done everything", } \\
\text { "felt better", "done my best", "trusted", "taken a load off me" or "helps me cope", } \\
\text { considered to be illustrative of this theme. }\end{array}$ \\
\hline Exclusions & $\begin{array}{l}\text { Instances from the raw data where participants referred to "happiness", } \\
\text { "understanding", "love", "hopefulness", or "acceptance" were not considered } \\
\text { to be related to this theme. Although there are similarities between these, they } \\
\text { are separated for the purposes of this study. }\end{array}$ \\
\hline Exceptions & $\begin{array}{l}\text { This refers to responses where one or more participants indicated opposite } \\
\text { responses to those of the majority of the participants. It may also indicate that } \\
\text { they did not express this particular emotional response at all. }\end{array}$ \\
\hline
\end{tabular}

In total, ten mothers reported experiencing feelings of relief, seven feeling relieved that their child was at the 'remedial' school, because they trusted the teachers a great deal. They felt that the teachers would pick up any areas of difficulty and address them. Mothers reported feeling relaxed, knowing that the teachers knew how to handle children with these special needs. They felt that this trust was important in contributing towards their feelings of relief. This sub-theme is supported by the following quotations:

- 'I've trusted [the teacher] because I think trust is a very important thing...I trust [the doctors]... when I walk out I don't wonder...it's the same at that school...I trust them...that's a nice feeling' (Participant 1, units $124 \& 126$ ).

- '...who says...this is what we're going to do...you need to trust that person. So we went from the one school feeling that we had placed our trust in the wrong place, to the new one that said this is our job, this is how we deal with it... (Participant 2, unit 102).

- '...the decision was made carefully... and I'll trust their judgment because the teachers are very clued up on remedial education... their opinion would be right' (Participant 4, units 42 \& 44).

- '... but I know they are working on it... which is a relief' (Participant 6, unit 68). 
- 'I just let it take it's course... the school will support her to do her best in class' (Participant 8, unit 40).

- 'I think positive was him being at [the remedial school]... I feel I don't have to worry as much as what I did because they know... I know they are doing their bit at school. I'm confident with what they are doing...' (Participant 9, unit 90).

- '...I'm actually feeling quite sort of relaxed about it at this stage...' (Participant 11, unit 34).

Six mothers reported feeling relieved when their child was accepted at the 'remedial' school, because they felt that it incorporated full, specialised 'remedial' support. Although this sub-theme may appear similar to the previous one, the preceding one emphasises relief as a result of trust in the teachers. This sub-theme emphasises relief associated with their child being accepted at the school and being able to attend it. These two sub-themes are closely related. This sub-theme is supported by the following quotations:

- '...the principal saw him and she saw his books and she said, no, he must come... and that was a relief, you know, it was a relief... when they said yes to [the remedial school], I thought this was a blessing...' (Participant 1, units 40 \& 42).

- 'She's gained an incredible amount of confidence from going to that school, which is fantastic for me. That's just taken a big load off me' (Participant 4, unit 78).

- 'With [him] being at [the remedial school], it has given him and me such insight and growth to his basic grounding. I do not believe he could have had this at any other school and am completely comfortable and proud of his achievements at [the remedial school]' (Participant 5, letter).

- 'When she got into [the remedial school]... it was like a relief...it doesn't matter what it costs, as long as she's happy... and she has been...'(Participant 6, unit 12).

- 'It was such a relief to put him in [the remedial school]...'(Participant 11, unit 32).

Seven mothers reported experiencing relief and comfort from knowing that they have done everything they could to help their child and from knowing that they have done the best for him or her. This sub-theme is supported by the following quotations:

- '...the sense that I've done everything I could've done... it made me feel better...' (Participant 1 , unit 62).

- '...I don't think there was much more that we could've done...' (Participant 4, letter).

- 'I know I do everything I can to help them through school...I do everything I can to help them have a good year at school...' (Participant 7, unit 50).

- '...just doing my best [has helped me to cope]' (Participant 8, unit 104).

- '... as a parent I've tried my best...' (Participant 9, unit 56).

- '...I've done the most I could...' (Participant 10, unit 100).

- 'I realise now that all mothers make mistakes...I will never be a perfect mother, but I do my best' (Participant 11, unit 42).

Two mothers reported feeling relief when they saw that the medication to help their child to concentrate was having positive benefits for the child. Their initial reluctance turned to relief as they saw how it helped their child to cope. This sub-theme is supported by the following quotations: 
- 'I wasn't very happy giving my child a chemical, yet I knew I had done absolutely everything that I could possibly do... that I couldn't do more for him... I knew I had to do it. I gave him the minimum dose and it works like a charm... if you look at his work from before and compare it to now, his writing is beautiful and he's very eager... he wants to learn' (Participant 1, unit 44).

- '...we said no because we're very anti drugs and stuff in our home, but last year we said we're going to test him on a quarter [medication] and see if there's a difference... and there was an incredible difference... his concentration, the way he wrote... he knew what he was doing...' (Participant 5, unit 8).

- '...I felt relieved that he could cope better at school... he'd come home and say, mommy, I didn't finish last...' (Participant 5, unit 14).

Two mothers reported feelings of relief in realising that their child's learning difficulties are not their fault or due to anything that they did wrongly. The one mother mentioned that this realisation was related to her having another child who coped well academically, where she came to realise that it was not her parenting skills that caused her child's learning difficulties, thus leading to a sense of relief. This sub-theme is supported by the following quotations:

- '...seeing that I have two kids and one is completely different to the other one Ihelps me to cope]... I can't believe I'm the same mother bringing up these two kids that are so completely different...'(Participant 10, unit 46).

- 'I feel relieved... because at least I don't blame myself anymore. Because I used to blame myself and think where did I go wrong and I realise now that all mothers make mistakes...I do my best' (Participant 11, unit 42).

One mother did not report experiencing a feeling of relief in response to her child's learning difficulties. She reported that she was very accepting of his learning difficulties from the start. This is supported by the following quotation:

- '...it didn't fuss me in the least, because...I knew that he was battling at a certain stage. Either he'd have to overcome it or that was the route we'd have to go through his schooling...no other way... I was very accepting from the start...' (Participant 3, units 14 \& 16).

\section{Acceptance}

'...wanting to try and fix it and get it right... maybe that's part of the acceptance thing... accepting that your child has this problem and that you're going to have to deal with it for the rest of their academic career and that's not a short-term thing...so I think I maybe struggled to deal with, maybe that's what I'm dealing with...acceptance... it takes a while to accept...' (Participant 2, units 68 \& 70). 
Table 6: Emotional response theme: Acceptance

\begin{tabular}{|l|l|}
\hline \multicolumn{2}{|c|}{ ACCEPTANCE } \\
\hline Definition & The act or process of accepting; favourable reception; approval (Morris, 1973:7). \\
\hline Indicators & $\begin{array}{l}\text { All the instances from the raw data where participants used phrases such as } \\
\text { 'accepting', 'can succeed', 'will have opportunities', 'realisation over time', 'fine } \\
\text { with it' or 'accepted it' were considered to be illustrative of this theme. }\end{array}$ \\
\hline Exclusions & $\begin{array}{l}\text { Instances from the raw data where participants referred to 'happiness', 'relief', } \\
\text { 'understanding' or 'hopefulness' were not considered to be related to this theme. } \\
\text { Although there are similarities between these, they are separated for the purposes } \\
\text { of this study. }\end{array}$ \\
\hline Exceptions & $\begin{array}{l}\text { This refers to responses where one or more participants indicated opposite } \\
\text { responses to those of the majority of the participants. It may also indicate that } \\
\text { they did not express this particular emotional response at all. }\end{array}$ \\
\hline
\end{tabular}

In total, six mothers reported experiencing feelings of acceptance, four saying that it took them a little time to accept the reality of their child's learning difficulties. They felt that it was easier to cope when there was an acceptance of one's child's difficulties as a long-term problem and a recognition of the fact that it is not the end of the world and that their child can still enjoy a fulfilling life. This sub-theme is supported by the following quotations:

- '...I have come to accept his difficulties as part of our lives. We have learnt to cope with it and now we can move forward... it is not going to go away... but we can work around it...'(Participant 1, letter).

- '...he will always need additional support, but he can actually succeed in life... it's not something that's going to stop him enjoying his life...not accepting the reality's not going to get you very far' (Participant 2, units $24 \& 26$ ).

- 'The fact that she would have to go to a special remedial school...was a realisation over a very long period of time that this would be the only solution for her... (Participant 4, letter).

- '...I thought it would be six months and it would be over...but they said it was a long-term problem...I just didn't think I wouldn't be able to help her faster...now I accept that it's always going to be there...' (Participant 6, unit 228).

Two mothers reported that they easily accepted their child's difficulties from the start. They were not ashamed of the fact that their child would have to go to a 'remedial' school. They knew that this was the best for their child and ignored others' views of the stigma attached. This sub-theme is supported by the following quotations:

- '...it didn't worry me in the least...it didn't worry me at all that he should go for an assessment or that he should go to a remedial school... there's a huge stigma attached to a kid going to a remedial school, but it didn't fuss me in the least, because...I knew that he was battling at 
a certain stage. Either he'd have to overcome it or that was the route we'd have to go through his schooling...no other way...I was very accepting from the start...'(Participant 3, units 14 \& 16).

- 'I've accepted his learning problem...I've really accepted it...I don't care that my son's at [the remedial school]...I'm not ashamed of it...I'm quite proud that we can afford to take him to that school that can help him' (Participant 10, unit 22).

Five mothers did not refer to the feeling of acceptance, either positively or negatively.

\section{Hopefulness}

'...I hoped against hope that she was going to move to grade one...you keep on hoping for a light and that she'll improve... which I also hope for, I think maybe one day, you know... something's going to kick in...' (Participant 4, unit 38).

Table 7: Emotional response theme: Hopefulness

\begin{tabular}{|c|l|}
\hline \multicolumn{2}{|c|}{ HOPEFULNESS } \\
\hline Definition & $\begin{array}{l}\text { Having or manifesting hope; inspiring, promising. Hope: To be confident; trust; } \\
\text { to look forward to with confidence of fulfilment; expect with desire (Morris, } \\
1973: 634) .\end{array}$ \\
\hline Indicators & $\begin{array}{l}\text { All the instances from the raw data where participants used phrases such as } \\
\text { "feel hopeful", "optimistic", "I'm hoping", "feel good about the future" or } \\
\text { "thought it would come right" were considered to be illustrative of this theme. }\end{array}$ \\
\hline Exclusions & $\begin{array}{l}\text { Instances from the raw data where participants referred to "happiness", "relief", } \\
\text { "understanding", "love" or "acceptance" were not considered to be related to } \\
\text { this theme. Although there are similarities between these, they are separated } \\
\text { for the purposes of this study. }\end{array}$ \\
\hline Exceptions & $\begin{array}{l}\text { This refers to responses where one or more participants indicated opposite } \\
\text { responses to those of the majority of the participants. It may also indicate that } \\
\text { they did not express this particular emotional response at all. }\end{array}$ \\
\hline
\end{tabular}

In total, eight mothers reported experiencing feelings of hopefulness, seven reporting feeling hopeful and optimistic about their child's future. They were confident that their child would be able to cope. This sub-theme is supported by the following quotations:

- 'I'm hopeful when I think about his learning difficulties... because I think that that school's wonderful...' (Participant 1, unit 50).

- 'I'm fairly optimistic about her future because she's not a stupid child...she's fairly bright...I don't think she'll ever do very well...but she'll cope' (Participant 6, unit 40).

- 'I'm hoping she'll come out of it...sometimes you need yourself to push yourself and I think she might do it...get to that stage' (Participant 6, unit 200). 
- 'I feel good about the future...I feel good because I think what they've done there for her...it's the best thing ever' (Participant 7, unit 28).

- '...I'm positive...I know that she'll go to high school... and she'll manage...I've got no problem about the future...' (Participant 8, units $34 \& 36$ ).

- '...I feel there's light at the end of the tunnel...' (Participant 9, unit 26).

- '...I hope it will be better...I hope that he'll get more responsibility in life...' (Participant 10, unit 40).

- 'I feel fine about his future...[he] has got an incredible character... he's just got such a generous heart...he's a good child... he's just rock solid...'(Participant 11, unit 44).

Two mothers reported that initially, when the difficulties were first diagnosed, they felt hopeful that their child would improve. They thought that their child was just developmentally slower in maturing. They felt hopeful that the difficulties were not a serious problem. This sub-theme is supported by the following quotations:

- 'I thought he was a late developer, because the other two were also late developers...'(Participant 1, unit 6).

- '...I read about the medication... and I was shocked...I really didn't want to go that route... a part of me was still hoping...I must just find the right way about it... that I'm going to help him cope...' (Participant 1, unit 38).

- '...hope, there's always hope... she probably will be fine...' (Participant 4, unit 16).

- '...to me it's just developmental... and that's why I keep on hoping...'(Participant 4, unit 74).

Three mothers did not report experiencing feelings of hopefulness, although neither did they report any feelings of hopelessness.

\section{Discussion of responses}

The results of this study, with the specific focus on the positive emotional responses, indicated that the most common joyful emotional responses expressed by the mothers were those of love and happiness. All the mothers reported the emotional response of love. Mothers mentioned that they felt that loving their child was a way of supporting him or her. The emotional response of love reported by the participants manifested themselves in a wide range of expressions. They expressed love in terms of admiration, adoration, pride in their children and also in terms of an appreciation of his or her unique personality.

All eleven mothers reported feelings of happiness, primarily in response to their child attending the 'remedial' school, as well as seeing the emotional improvement from being at the school, for example, increased self-confidence and happiness. Participants sometimes experienced frustration because of a lack of support, and then they experienced happiness with the support that was now accessible with their child being accepted at the 'remedial' school.

Relief was another very common emotional response reported by the mothers in this study. Ten mothers reported experiencing this emotion, primarily in relation to their child being accepted at the 'remedial' school, but also for some in that they felt they had done everything they possibly could have for their child. Others felt relieved, realising they were not to blame for their child's 
learning difficulties. Silver (1998) is supportive of this result and mentions that some parents experience a feeling of relief and comfort when they learn of their child's difficulties, in the sense that they now have an answer for what they always felt was going wrong. This opinion is shared by Smith (1998), who states that some parents are relieved when told that their child has learning difficulties as it confirms their suspicions.

The next most commonly reported joyful emotional response, which was reported by eight mothers, was hopefulness. The mothers in this study specifically referred to feeling hopeful and optimistic about their child's future, feeling positive about their child being able to cope. Some mentioned feeling hopeful when the initial diagnosis of learning difficulties was made, thinking everything would come right. None of the available literature consulted during this study refers to feelings of hopefulness. On the contrary, there is reference to feelings of hopelessness (Goldstein \& Mather, 1998; Silver, 1998).

Six mothers reported feelings of understanding. Mothers reported that reading up on their child's difficulties and speaking to other mothers helped them to gain a better understanding of their child and what he or she was going through. They reported that this helped them to be able to give their child better support. In addition to this, having learning difficulties themselves helped mothers to better understand their child. This emotional response was not mentioned in any of the available literature consulted.

Six mothers in this study also mentioned feelings of acceptance, most explaining that it took them some time to accept their child's learning difficulties. Few mothers reported acceptance from the outset. Crow and Crow (1997) note that some parents do not adjust well to accepting that their child has learning difficulties. This, they explain, can seriously interfere with their child's day-today functioning and with his or her ability to successfully handle life's challenges and opportunities. These parents are also not fully available to their children. In relation to this, Tanguay (2002) mentions that some parents who have difficulty accepting that their child has learning difficulties may experience denial or minimise their child's difficulties. Silver (1998) also refers to denial, but mentions that parents gradually work through their grief and begin the long mourning process, where they slowly accept the loss of their ideal child and move on with life and the challenges of helping him or her.

\section{Guidelines for dealing with mothers of children with learning difficulties}

These results indicate that although mothers may experience complex emotions in response to their child with learning difficulties, not all their emotions are negative. There are a number of positive, joyful emotional responses that are part of the complexity of emotions. Most literature appears to place more focus on the negative emotional responses experienced by mothers of children with learning difficulties, with only a few positive emotional responses being explored. Understanding of their child's difficulties appears to play a pivotal role in mothers' experience of either positive or negative emotions. It thus becomes the task of those in the field of learning difficulties to draw on the strengths of mothers of children with learning difficulties. In addition to this, there is a need to effectively explain to them what their child's learning difficulties entail, in order to understand how their child's difficulties are to be addressed. 
Finally, it should be noted that the emotional responses of the mothers (as captured in this study) did not always distinguish between their emotional responses towards their children, and their emotional responses towards the school, where the necessary support was provided for their children. This indicates the complexities involved in dealing with the challenges of a child with learning difficulties and eliciting the necessary support.

From the preceding discussion it is clear that those who work in the field of learning and learning difficulties may benefit from having a nuanced understanding of the emotional responses of mothers to their children with learning difficulties. This is especially significant during the diagnosis of learning difficulties. By being aware of the emotional responses of mothers, including the positive emotional responses, helping professionals may be able to support such mothers more effectively.

Mothers in this study expressed the need for helping professionals to provide them with more information on what their child was experiencing, so even while mothers are experiencing a range of emotional responses to the diagnosis, it seems that a primary directing motivation is still towards supporting their child most effectively. The focus in the literature on parents of children with learning difficulties mentioned earlier in this article (e.g. on providing support for their child) therefore seems apposite. The mothers in this study expressed a strong inclination towards understanding what learning difficulties in their child really means, as well as the implications concerning what is needed for their child and what the future holds. Supporting mothers through increased understanding and knowledge may therefore lead to an increased openness, willingness and capacity on the part of mothers to be able to support their child with learning difficulties more effectively. Yet, the complexity of the emotional responses of the mothers needs to be integrally acknowledged within this process. It is clear that helping professionals play a vital role in supporting mothers to understand their child's difficulties, as well as in fostering the mothers' ability to support their children effectively. Recognition of the central role of maternal emotional responses may facilitate this process even further.

\section{Conclusion: Mothers are positive too}

There is a tendency to understand the world in terms of available narratives, i.e. in terms of what one expects mothers of children with learning difficulties to experience emotionally. For example, most would expect such mothers to go through a very difficult, emotionally upsetting time. The results of this broader study (Williams, 2004) indicate that although these mothers do experience many negative emotions, the results discussed in this article indicate that they also experience a number of positive emotions in response to their child with learning difficulties. The results thus support the recent trend in psychology to move towards a more strength-focused and solutionfocused emphasis, that seeks to find the positives within a challenging situation. 


\section{References}

Aguinis, H. and Henle, C.A. (2002) Ethics in research, in S.G. Rogelberg (ed.) Handbook of research methods in industrial and organizational psychology, pp. 34-56. Oxford: Blackwell Publishers.

Boyatzis, R.E. (1998) Qualitative information: Thematic analysis and code development, London: Sage Publications.

Christenson, S.L. \& Sheridan, S.M. (2001) Schools and families: creating essential connections for learning, London: The Guilford Press.

Clandinin, D.J. and Connelly, F.M. (2000) Narrative inquiry: Experience and story in qualitative research, San Francisco: Jossey-Bass Publishers.

Creswell, J.W. (1998) Qualitative inquiry and research design: Choosing among five traditions, London: Sage Publications.

Creswell, J.W. (2002) Narrative research designs, in J.W. Creswell (ed.) Educational research, pp. 520-558. Columbus: Merrill Prentice Hall.

Crow, G.A. and Crow, L.I. (1997) Helping parents cope with children's adjustment problems: An advice-giving guide for professionals, Illinois: Charles C. Thomas Publisher, Ltd.

Danford, S. (2006) From Epistemology to Democracy. Remedial and special education, 27(6), pp. $337-345$.

Egan, G. (2002) The skilled helper: A problem-management, and opportunity-development approach to helping, CA: Brooks/Cole Thomson Learning.

Ezzy, D. (2002) Qualitative analysis: Practice and innovation, London: Routledge.

Goldstein, S. and Mather, N. (1998) Overcoming underachieving: An action guide to helping your child succeed at school, New York: John Wiley \& Sons, Inc.

Leifield, L. \& Murray, T. (1995) Advocating for Aric: Strategies for Full Inclusion. In B.S. Swadener \& S. Lubeck (Eds). Children and Families "At Promise": Deconstructing the Discourse of Risk. New York: State University of New York Press.

Prinsloo, E. (2005) Socio-economic barriers to learning in contempory society. In Landsberg, E. (Ed.) Addressing barriers to learning. Pretoria: Van Schaik Publishers.

Salend, S.J. (2005) Creating inclusive classrooms ( $5^{\text {th }}$ Ed.), New Jersey: Pearson Education, Inc.

Silver, L.B. (1998) The misunderstood child: Understanding and coping with your child's learning disabilities ( $3^{r d}$ Ed.), New York: Times Books, Random House Inc.

Smith, C.R. (1998). Learning disabilities: The interaction of learner, task and setting (4 ${ }^{\text {th }}$ Ed.). Boston: Allyn \& Bacon.

Tanguay, P.B. (2001) Nonverbal learning disabilities at home: A parent's guide, London: Jessica Kingsley Publishers.

Williams C.M. (2004) A narrative study of the emotional responses of mothers' to children with learning difficulties, Unpublished M Ed-dissertation, University of Pretoria. 


\section{Cheryl Williams}

Department of Educational Psychology,

Faculty of Education,

University of Pretoria

\section{Irma Eloff}

Department of Educational Psychology,

Faculty of Education,

University of Pretoria,

Telephone: 0124205503

E-mail: irma.eloff@up.ac.za 